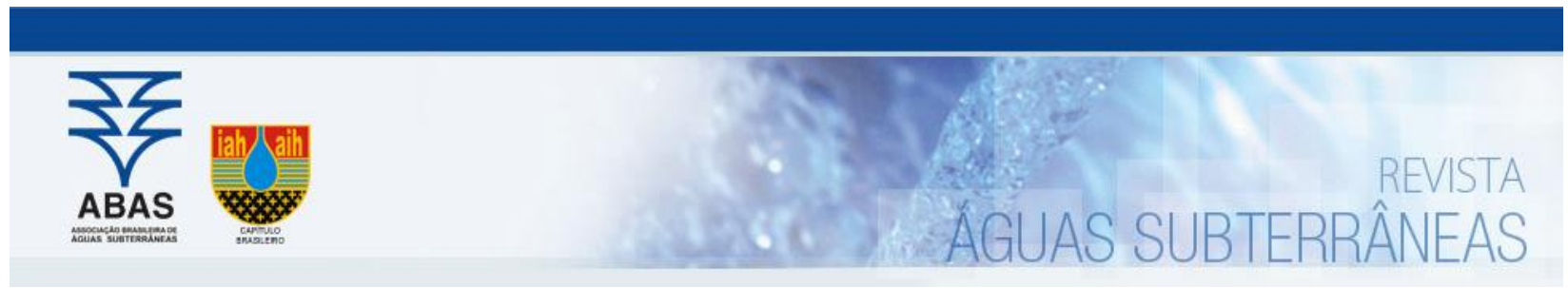

Artigos

\title{
Utilização conjunta de dados de fraturas e lineamentos para indicação de fatores de zoneamento de aquíferos fraturados
}

\section{Fracture and lineament data used together to indicate fractured aquifer zoning factors}

\author{
Ana Maciel de Carvalho1; Amélia João Fernandes²; Luis de Almeida Prado Bacellar1; Victor Câmara Maurer1; Paula Ribeiro \\ de Melo1; Tiago Borges ${ }^{\circledR}$
}

1 Universidade Federal de Ouro Preto (UFOP), Ouro Preto, MG.

2 Instituto Geológico do Estado de São Paulo, São Paulo, SP.

3 Construtora Queiroz Galváo.

anamcarv@gmail.com, amelia.jfernandes@gmail.com, bacellar@ufop.edu.br, camaramaurer@gmail.com, paula.melo@aluno.ufop.edu.br, tiago.borges@queirozgalvao.com

Palavras-chave:

Aquíferos fraturados;

Lineamentos;

Serra do Mar;

Litoral Norte do Estado de São Paulo.
Resumo

O traçado de lineamentos tem sido utilizado para inferir trends estruturais, tratando-se de uma etapa preliminar nos estudos de aquíferos fraturados. Objetivando avaliar a utilização dessa ferramenta para zoneamento de aquíferos fraturados, adotou-se o seguinte método: análise de fraturas; elaboração de mapas de lineamentos em várias escalas; e elaboração de rosetas de lineamentos para unidades litológicas e geomorfológicas. Os resultados indicam que: o levantamento sistemático de fraturas é fundamental para confirmar a correlação entre trends de lineamentos e de fraturas; dados de fraturas devem ser coletados nos vários tipos litológicos de uma região, pois alguns grupos de fraturas podem ser exclusivos ou mais frequentes em determinadas unidades litológicas; os lineamentos devem ser interpretados em várias escalas, incluindo as de detalhe compatível com o objetivo do estudo; as rosetas de soma de comprimentos dos lineamentos são mais adequadas para identificar as intensidades dos vários trends; mapas litológicos e morfológicos (formas de relevo, ICR e padrões de drenagens) devem ser testados para delimitar domínios estruturais (zoneamento) em aquíferos fraturados. Concluiu-se que, com a identificação de trends de fraturas e de lineamentos, bem como de fatores que podem ajudar na delimitação de regiões com configurações distintas de fraturas, um passo importante foi dado para se chegar à delimitação de domínios estruturais em aquíferos fraturados. Essa delimitação é fundamental para elaboração de modelo hidrogeológicos e minimização de riscos em obras de engenharia.

\begin{abstract}
Lineament tracing has been used to infer structural trends, and it is a preliminary step in studies of fractured aquifers. In order to evaluate the use of this tool for zoning fractured aquifers, the following methods were adopted: survey and analysis of fractures; elaboration of lineament maps at various scales; and elaboration of lineament rose diagrams for lithological and geomorphological units. The results indicate that: the systematic survey of fractures is essential to confirm the correlation between lineament and fracture trends; fracture data must be collected on the various lithological types of a region, as some fracture sets may be exclusive or more frequent in certain lithological units; lineaments must be interpreted at various scales, including those that are suitable for the purpose of the study; the lineament total length rose diagrams are more suitable for identifying the intensities of the several structural trends; lithological and morphological maps (eg relief forms, ICR and drainage patterns) should be tested to delimit structural domains (zoning) in fractured aquifers. It was concluded that, with the identification of fracture trends and lineaments, as well as the identification of factors that have the potential to delimit regions with distinct fracture configurations, a first and fundamental step was taken towards the delimitation of structural domains in fractured aquifers. This delimitation is fundamental for numerous applications, including the elaboration of hydrogeological models and minimization of risks in engineering works.
\end{abstract}

\section{INTRODUÇÃO}

A constituição litológica pode influenciar significativamente a configuração do sistema de fraturas em aquíferos fraturados (COOK, 2003; DUARTE COSTA, 2008; FERNANDES et al.,
2021), e o conjunto de estruturas em uma rocha podem condicionar padrões de drenagem e unidades de relevo, sendo que as drenagens são mais sensíveis a movimentações tectônicas mais recentes (HIRUMA e RICOMINI, 1999). Nesse sentido, trabalhos que visem o zoneamento ou identificação 
de domínios estruturais em aquíferos fraturados devem considerar os tipos litológicos e as unidades geomorfológicas.

Grandes obras de engenharia frequentemente cortam maciços de rochas cristalinas e, para otimizar os projetos, evitar acidentes e mitigar problemas ambientais é necessário conhecer a configuração da rede de fraturas.

Uma forma preliminar de identificar trends de estruturas de uma região é o traçado de lineamentos, pois em geral estes expressam estruturas geológicas (HOBBS, 1904; O'LEARY et al., 1976), realçadas por feições morfológicas (drenagens retilíneas, quebras de relevo e escarpas acentuadas, e topos retilíneos de morros), havendo inúmeros exemplos de trabaIhos com aplicação em hidrogeologia (MABEE; HARDCASTLE, 1997; FERNANDES; RUDOLPH, 2001) e em obras de engenharia (MABEE et al., 2002; UMILI et al., 2018).

O objetivo deste artigo é avaliar em que medida o uso conjunto de levantamentos de fraturas e de lineamentos, integrados à análise de trends estruturais em unidades litológicas e geomorfológicas (padrões de drenagens, rugosidade e formas de relevo), é útil para identificar domínios estruturais com configurações distintas de sistemas de fraturas, ou seja, para o zoneamento preliminar de aquíferos fraturados. Este pode ser um primeiro passo para delimitar domínios hidro-estruturais, definidos aqui como volumes do aquífero em que as principais características geométricas da rede conectada de fraturas e a orientação dos caminhos preferenciais de fluxo mantêm-se relativamente homogêneos (SURRETTE; ALLEN, 2008; CAINE e TOMUSIAK, 2003).

A aplicação deste método poderá auxiliar na pesquisa de água subterrânea em aquíferos fraturados e na execução de grandes obras de engenharia, como túneis e barragens, ao ajudar a prever trechos com fluxos imprevisíveis e intensos de água, que constituem um dos grandes desafios para estas atividades (MABEE et al., 2002).

\section{2. ÁREA DE ESTUDO}

A área de estudo, com $80 \mathrm{~km}^{2}$, se situa no litoral norte do Estado de São Paulo (Figura 1), abrangendo o trecho de duplicação da rodovia Tamoios (SP-99), com extensão total de $21,5 \mathrm{~km}$.

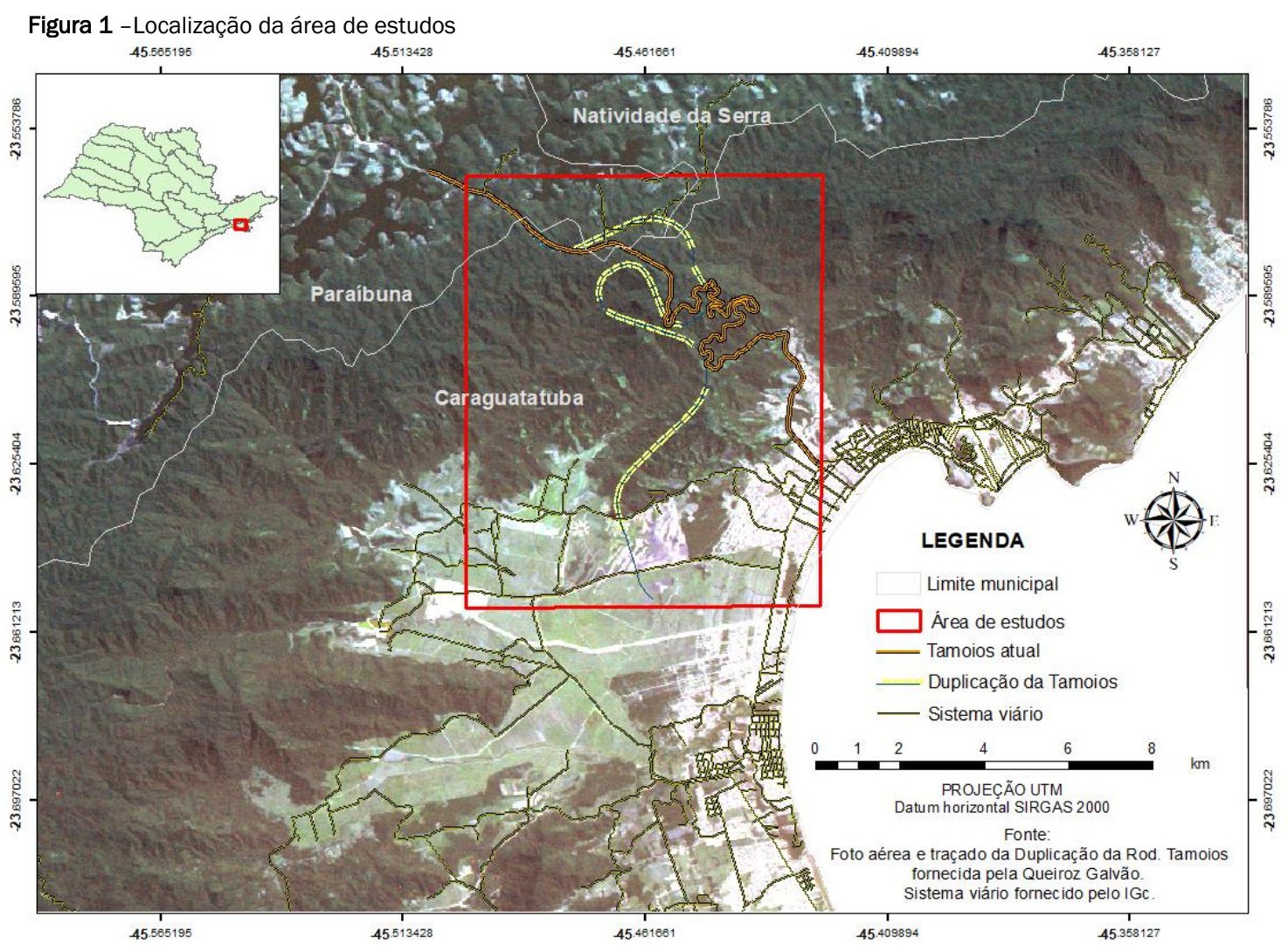

Fonte: Foto aérea e traçado fornecido pela Queiroz Galvão 


\subsection{Geologia}

A área se insere no Cinturão Ribeira (HASUI et al., 1981), do segmento central da Província Mantiqueira, um sistema orogênico de idade neoproterozóica, relacionado ao Gondwana Ocidental (ALMEIDA et al., 1977).

O mapa geológico disponível para a região é o de CHIODI FILHO et al. (1983), em escala 1:50.000 e apresentado no item de Resultados. As 8 unidades litológicas desse mapa podem ser agrupadas em três tipos litológicos principais, todos de idade pré-cambriana: granitos, ortognaisses e rochas paraderivadas. Zonas de cisalhamento, de direção ENE e de idade cambro-ordoviciana, constituídas principalmente por milonitos (SADOWSKI, 1991) destacam-se como grandes lineamentos. A foliação das rochas metamórficas apresenta trend geral ao redor de N60E. A direção do SHmax (esforço máximo horizontal) atual, para a região, seria NE (ASSUMPÇÃO et al., 2016). Na planície costeira ocorrem sedimentos inconsolidados holocênicos, distribuídos nas calhas de drenagens e baixadas litorâneas.

\subsection{Geomorfologia e hidrografia}

A região insere-se na unidade geomorfológica da Serra do Mar, formada entre o Cretáceo Superior e o Paleoceno (SIQUEIRA; HACKSPACHER, 2011), dividida em duas grandes unidades de relevo: i) planalto, que corresponde à superfície de topo da Serra do Mar; e ii) encosta, formada por escarpas festonadas recortadas, com espigões que se projetam até a linha de costa. A unidade de encosta termina na planície litorânea, com limites bruscos ou cobertos por rampas de colúvio. (CHIODI FILHO et al., 1983).

O padrão de drenagens do tipo retangular é predominante na unidade de encosta e denota um controle estrutural exercido por importantes zonas de cisalhamento e falhas (CHRISTOFOLETTI, 1980). Em geral, os rios nascem no alto da Serra e, chegando na planície, tornam-se meandrantes, desaguando em praias fechadas e baías.

\subsection{Aspectos Hidrogeológicos}

$\mathrm{Na}$ área ocorre o Sistema Aquífero Cristalino (SAC), do tipo fraturado. Neste, o manto inconsolidado (coberturas inconsolidadas e materiais de alteração) pode formar pequenos aquíferos descontínuos que irão contribuir para a recarga do aquífero fraturado e para o fluxo de base dos rios. A recarga de água subterrânea é favorecida pela alta pluviosidade, mas as bacias são de área limitada, de modo que, a disponibilidade hídrica pode ser menor que a esperada (DAEE, 2005).

O potencial hidrogeológico do SAC, no Estado de São Paulo, foi avaliado por Fernandes et al. (2005, 2007), com dados de capacidade específica e vazão de quase mil poços, que exibiram valores predominantes entre 0,01 e $0,67 \mathrm{~m}^{3} / \mathrm{h} / \mathrm{m}$ e 1 e $23 \mathrm{~m}^{3} / \mathrm{h}$, respectivamente. A grande variação de produtividade é reflexo da anisotropia e heterogeneidade do meio fraturado. Estes autores concluíram que a variação da potencialidade no SAC é mais influenciada por blocos geológicos, delimitados por grandes estruturas e lineamentos e, em seguida, pela litologia, com granitos maciços menos produtivos que gnaisses e metassedimentos.

\section{MATERIAIS E MÉTODOS}

O trabalho contemplou a coleta e análise de dados de fraturas em campo e o traçado de lineamentos em imagens de sensoriamento remoto e modelos digitais de terreno e de superfície. Com estes dados, foram elaboradas rosetas de lineamentos e fraturas para áreas constituídas por diferentes unidades litológicas, geomorfológicas (tipos de relevo), de índice de rugosidade e de padrões de drenagem.

Foram utilizados os mapas geológico e geomorfológico de CHIODI FILHO et al. (1983) e de drenagens do Instituto Geográfico e Cartográfico (IGC), todos na escala 1:50.000. Os mapas de lineamentos, de padrões de drenagens e de Índice de Concentração de Rugosidade (ICR) foram elaborados neste trabalho. Técnicas de Sistema de Informações Geográficas (SIG) auxiliaram no tratamento dos dados.

\subsection{Levantamento e análise de fraturas}

O método empregado foi o de levantamento em linha de varredura (scanlines), aplicado de forma sistemática em 11 scanlines, distribuídas em três afloramentos adjacentes, ao longo da rodovia. As fraturas foram plotadas em estereogramas, elaborados para cada local, utilizando o software DIPS 6.0 (ROCKSCIENCE, 2013). $O$ viés de orientação, resultante da subamostragem das fraturas com direção próxima da linha de levantamento, foi corrigido seguindo o método de PINO et al. (2019).

A identificação de vários grupos de fraturas foi visual, método utilizado por diversos autores (MABEE e HARDCASTLE, 1997; FERNANDES et al., 2016). 0 termo grupo foi utilizado como sinônimo de família, este comumente usado por outros autores para fraturas cogenéticas. Embora as fraturas de um mesmo grupo possam ser contemporâneas, isto não deve ser tomado como uma premissa. Os limites entre um grupo e outro correspondem a porções do estereograma em que as densidades de contorno diminuem de forma notável. A direção média de cada grupo é a média ponderada do seu intervalo de direções, calculada individualmente para cada grupo de acordo com a predefinição dos intervalos em estereogramas. Este procedimento foi aplicado às fraturas de mergulhos elevados a subverticais.

\subsection{Análise de lineamentos}

O método de traçado de lineamentos considerou quatro aspectos: i) fraturas de baixo mergulho em geral não se manifestam como lineamentos, principalmente em relevo mais acidentado; ii) regiões com manto inconsolidado mais espesso em geral apresentam menor densidade de lineamentos, o que não necessariamente corresponde a menor densidade de fraturas nas rochas subjacentes; iii) o realce das estruturas sob a forma de lineamentos tende a ser menor nas áreas de relevo mais suave, onde os processos 
erosivos são menos intensos e as estruturas menos realçadas, resultando em menor densidade de lineamentos; e iv) o traçado de lineamentos depende da escala, e lineamentos contínuos, que refletem estruturas regionais, tendem a ser mais notáveis em escalas pequenas, ao passo que escalas maiores ressaltam lineamentos menores. FERNANDES e RUDOLPH (2001) concluíram que em áreas de relevo suave (colinas pequenas a amplas), a delimitação de domínios estruturais homogêneos mostrava-se inviável.

Devido à influência da escala, foram selecionados modelos digjtais e imagens em escalas 1:10.000, 1:30.000 e 1:50.000 para o levantamento de lineamentos. As escalas 1:30.000 e 1:50.000 tiveram lineamentos traçados em Modelos Digitais de Elevação (MDE) e de Terreno (MDT) confeccionados, respectivamente, a partir da imagem de satélite Alos Palsar (MDE) e das curvas de nível dos mapas topográficos do IGC (MDT). Para essas duas escalas, os lineamentos foram realçados em superfície a partir de iluminações provenientes de Norte, N45E, Leste e N45W. Na escala 1:10.000, os lineamentos foram traçados diretamente na imagem pancromática do satélite CBERS-4/ PAN-5M, com visada lateral de +-32 graus. As imagens Alos Palsar e CBERS-4/ PAN-5M possuem, respectivamente, 12,5 e 5 metros de resolução espacial (INPE, 2019).

O traçado dos lineamentos foi manual, utilizando o programa ArcGIS 10.1. A ferramenta AzimuthFinder 1.1 (QUEIROZ et al. 2014) permitiu a tabulação dos azimutes para a elaboração de diagrama de rosetas das direções de lineamentos, tanto para frequência (número de traços) como para comprimento. Neste último caso, as pétalas do diagrama de roseta não representam a somatória do comprimento total por direção, pois utilizou-se o método de QUEIROZ et al. (2014), em que o comprimento de um lineamento é a quantidade de vezes que ele contém o menor lineamento da área multiplicada pelo comprimento deste.

Os diagramas de rosetas de lineamentos foram elaborados com o software Openstereo 2.0 (GROHMANN E CAMPANHA, 2010) para as diferentes escalas e para as diferentes unidades em cada mapa: litológico, geomorfológico (tipos de relevo), Índice de Concentração de Rugosidade (ICR) e de padrões de drenagem. Os trends (intervalos de direções) nos vários diagramas de rosetas de lineamentos foram avaliados com relação aos grupos de fraturas identificados em afloramentos.

\subsection{Elaboração de mapa de Índice de Concentração de Rugosi- dade (ICR)}

Além do mapa geomorfológico disponível em escala regional, empregou-se um parâmetro morfométrico adicional, o ICR, que expressa diferentes graus de dissecação do relevo (SAMPAIO e AUGUSTIM, 2014). A elaboração do mapa de ICR resultou da transformação do MDE, da imagem Alos Palsar, em valores de declividade convertidos para o formato vetorial. A partir do arquivo vetorial, aplicou-se o Estimador de Densidade por Kernel, resultando em novo arquivo matricial, onde cada pixel apresenta a soma dos valores de declividade de todos os pixels com distância inferior ao raio definido, 564 m, conforme HORTON (1945). O resultado é nor- malizado para se obter faixas de ICR aplicáveis e comparáveis em qualquer estudo (SAMPAIO e AUGUSTIM, 2014).

O ICR corresponde, portanto, a valores de declividades somados dentro de uma determinada área (rugosidade do relevo). Os valores de ICR variam de próximo a zero, para áreas predominantemente planas, até aproximadamente infinito, para áreas com relevo muito acidentado, baseado na variação da declividade $(0 \%$ para $0^{\circ}, 100 \%$ para $45^{\circ}$, e $\propto$ para $90^{\circ}$ ). Para esse estudo foi utilizado o padrão ICR, subdividido em classes normalizadas: Muito Baixo, Baixo, Médio, Alto e Muito Alto.

\subsection{Delimitação de padrões de drenagens}

Os padrões de drenagens foram identificados no mapa de hidrografia, do IGC na escala 1:50.000, e no MDE gerado na imagem Alos Palsar. A diferenciação dos padrões considerou as propriedades indicadas em HOWARD (1967) e SOARES e FIORI (1976), que são: a densidade de drenagens (baixa, média e alta); o grau de estruturação (fraco, moderado e forte); a assimetria (fraca ou forte); e a sua estrutura (dendrítica, paralela, treliça, retangular, radial, anelar, multibacinal, contorcido, complexo e palimpsesto).

\section{RESULTADOS}

\subsection{Grupos de fraturas}

Os dados de fraturas foram coletados em onze scanlines que se agrupam da seguinte forma: SL 1 a 4 em gnaisse fino alterado, no local A, com direção N40E e extensão total de 92,2 metros; SL 5 a 9 em biotita gnaisse fino acinzentado, no local $B$, com direção N40W e extensão de 63,4 metros; e SL 10 e 11 em biotita gnaisse cinza com bandas quartzo-feldspáticas, no local C, com direção N70W e extensão de 69 metros (Figura 2).

Como as scanlines em B e C estão próximas, e têm direção semeIhante, foram interpretadas em conjunto, após a correção de viés (Tabela 1 e Figura 3). Nos estereogramas e rosetas da Figura 3 consideram-se apenas as fraturas com mergulho maior que $60^{\circ}$, pois isto permite uma comparação direta com as direções de lineamentos.

O grupo 1 (G1) tem direção relativamente constante e média de N64E e N68E, ocorrendo em todos os locais analisados, sendo paralelo à atitude média da foliação (N60E/87SE) dos gnaisses. Os grupos 2 e 3 (G2 e G3) apresentam direção variável e são muito mais evidentes no local A. O G2 tem direções médias de N5W e N6W, é mais disperso e varia entre N30W-N20E; o G3 apresenta menor espalhamento, possui direção média de N46W e varia entre N30-60W. O G3 não foi amostrado nas scanlines dos locais $\mathrm{B}$ e $\mathrm{C}$, e isto provavelmente se deve ao fato de serem subparalelas à direção desse grupo de fraturas. No grupo 4 (G4) as fraturas são próximas a E-W e direção pouco variável com média N82E e N86E. Fraturas de baixo ângulo $\left(<=30^{\circ}\right)$ são abundantes no local $B$, com direção ENE ( N6OE) e mergulham para NNW ou 


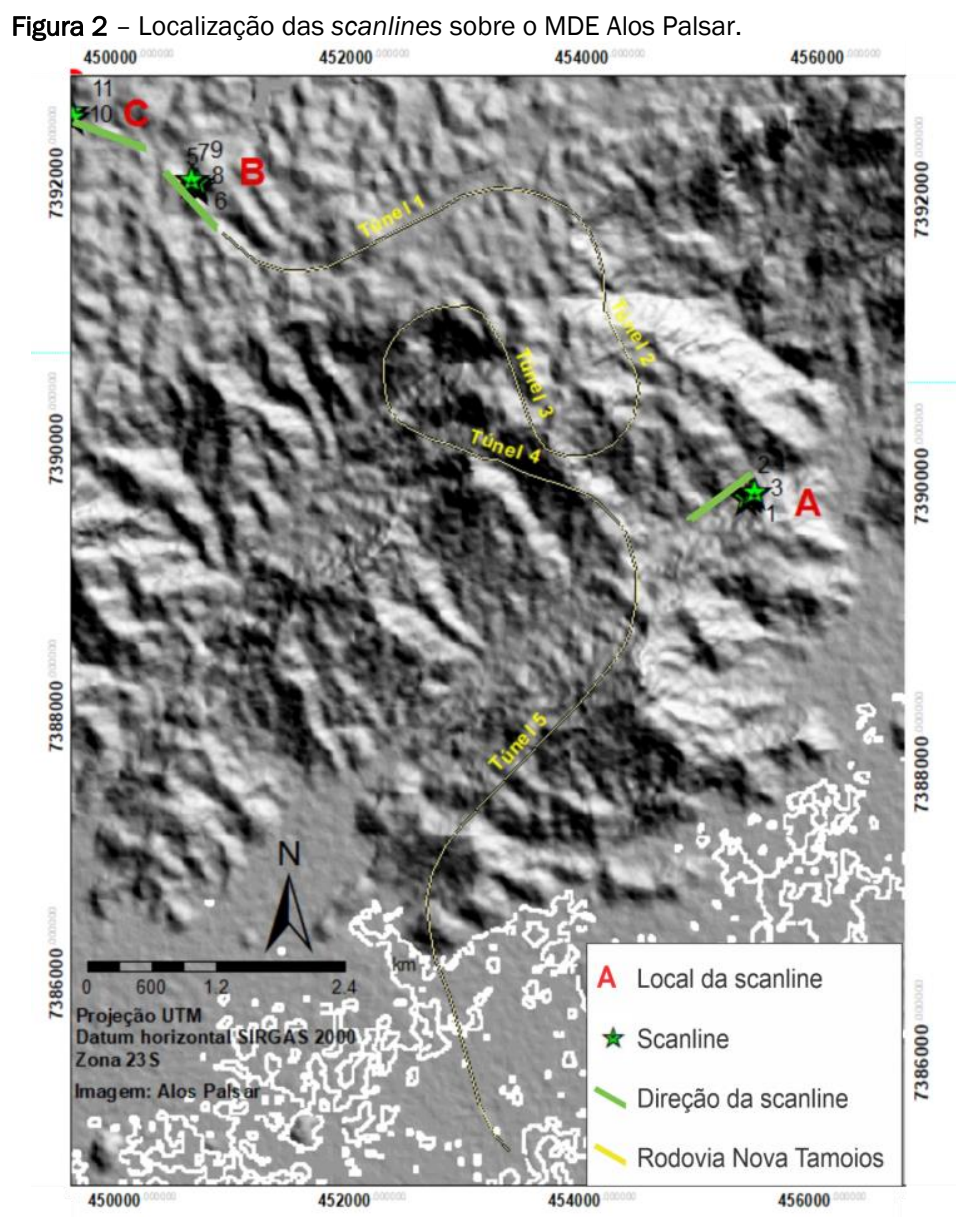

Fonte: Imagem Alos Palsar

As fraturas do G1 são, em geral, planas com comprimento maior que $8 \mathrm{~m}$, pois terminam além dos limites dos afloramentos. Essas fraturas possuem estrias de baixo ângulo a horizontais (255/08 a $242 / 18$ ) indicando movimentação transcorrente. As fraturas do G1 e G2 apresentam as maiores evidências de fluxo de água (oxidação das paredes da fratura e presença de vegetação) e as do G4 são as menos expressivas na área (Tabela 1). A direção do
SHmax atual indica fraturas no quadrante NE como as mais propensas à reativação e a serem mais transmissivas; isso está de acordo com o fato das fraturas do G1 e a direção NNE (parte do G2) apresentarem mais evidências de fluxo. A Figura 4 ilustra trechos das scanlines dos locais $B$ e $C$ indicando as fraturas e seus respectivos grupos.

Tabela 1- Características dos grupos de fraturas.

\begin{tabular}{llll}
\hline Grupo & \multicolumn{1}{c}{ Grupo de Fraturas } & \multicolumn{1}{c}{ Comprimento $(\mathrm{m})$} & \multicolumn{1}{c}{ Evidências de fluxo de água } \\
\hline G1 & N60-80E / subvertical & 2 a até pelo menos 8 & $40 \%$ oxidação e 10\% vegetação \\
G2 & N20W-N20E / subvertical & 1 a até pelo menos 8 & $20 \%$ oxidação e < 10\% vegetação \\
G3 & N30-60W / subvertical & 2 a até pelo menos 8 & Sem preenchimento ou oxidadas e \\
G4 & N80-90E / subvertical & 1 a até pelo menos 7 & $10 \%$ oxidação e sem vegetação \\
\hline
\end{tabular}

Fonte: Elaborada pelos autores 
Figura 3 - Grupos de fraturas com alto mergulho $\left(>60^{\circ}\right)$ após correção de viés, G1 a G4, nos locais A, B e C indicadas por diagramas de a) densidade, e b) rosetas

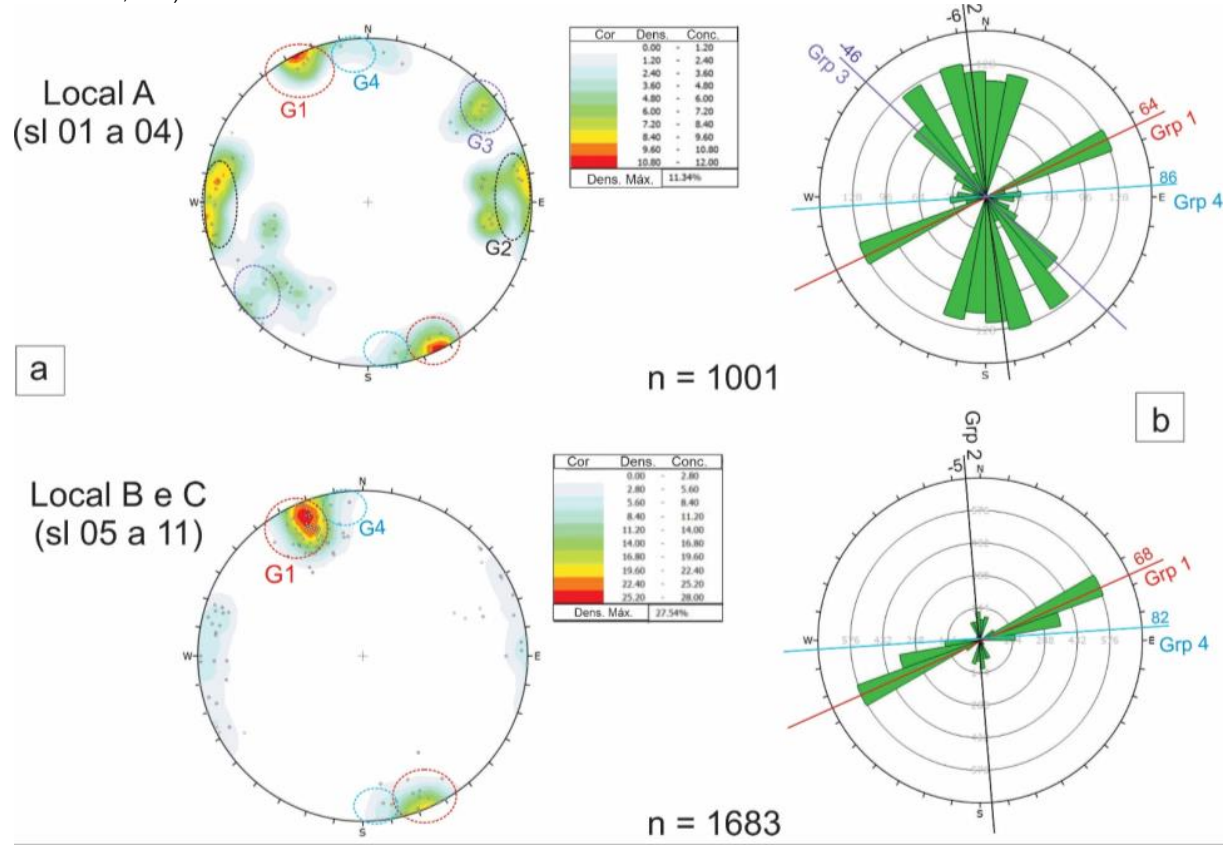

Fonte: Elaborada pelos autores

Figura 4 - Scanlines com atitudes de fraturas e seus respectivos grupos (G1 a G4). a) Trecho das scanlines 7 a 9, no local B; e b) Trecho da scanline 11 , no local $\mathrm{C}$

a)

N40W

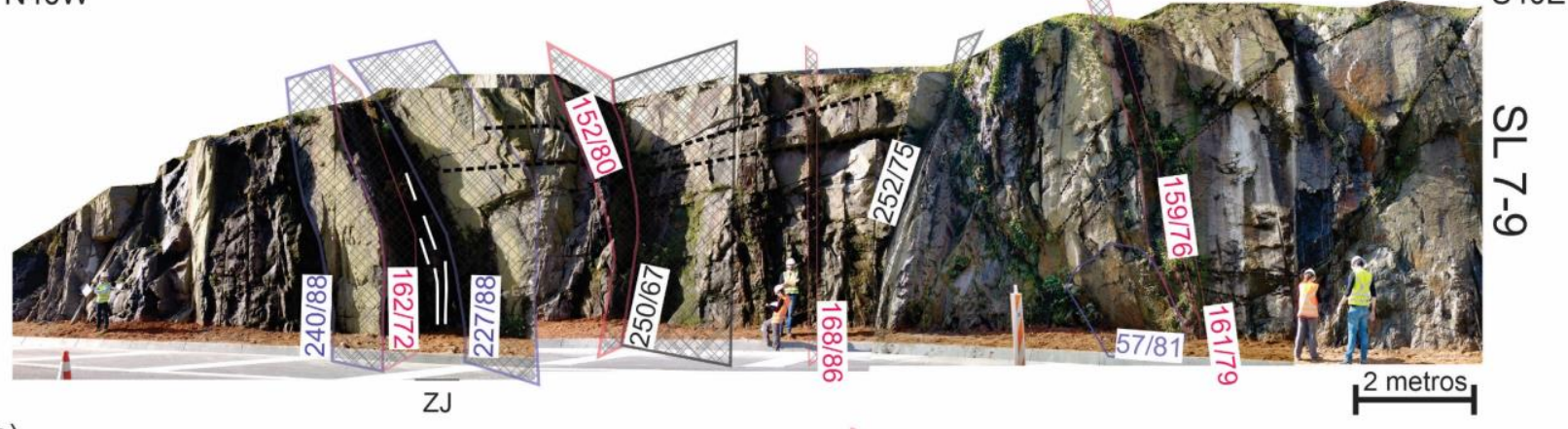

b)

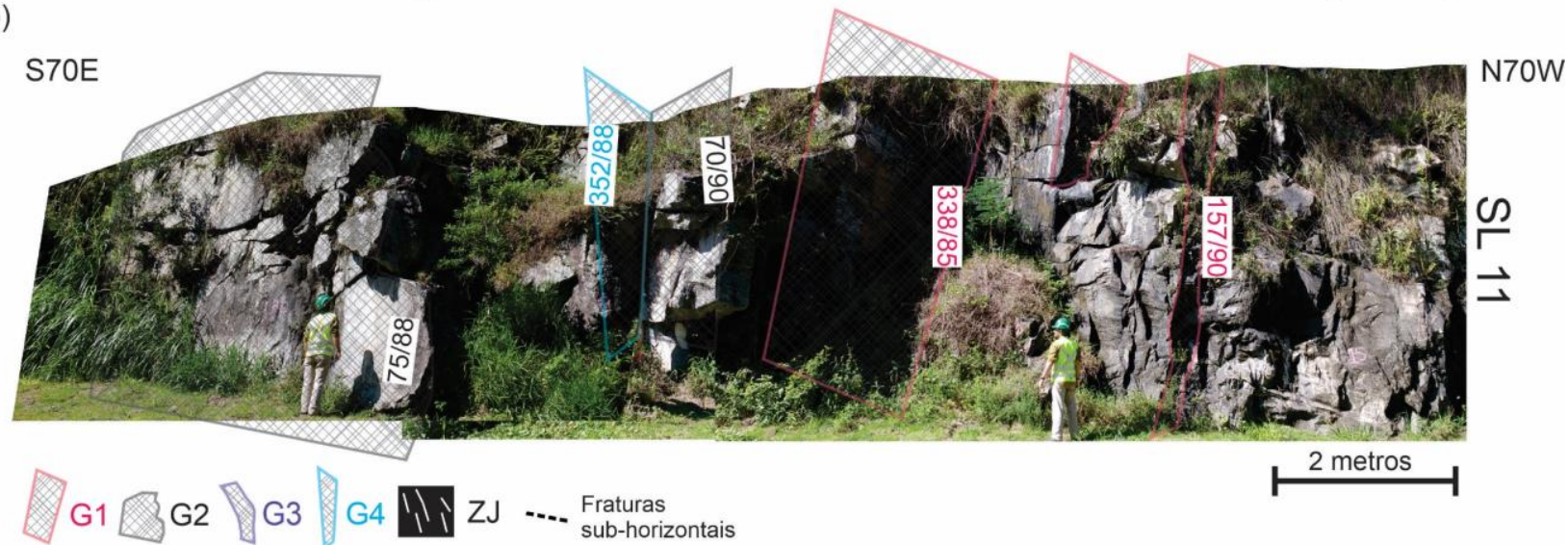

Fonte: Fonte: Elaborada pelos autores 


\subsection{Lineamentos}

Foram traçados 380 lineamentos na escala 1:50.000; 425 lineamentos, na escala 1:30.000; e 784 lineamentos, na es cala 1:10.000 (Figura 5). As rosetas de frequência (Figura 6) mostram um espalhamento maior que as de comprimento e, em especial, nota-se um grande espalhamento das direções NW, principalmente nas escalas 1:50.000 e 1:30.000.

Figura 5 - Mapas de lineamentos traçados em diferentes escalas, com indicação dos principais trends, e os locais (A, B, C) das scanlines: a) Escala 1:10.000, imagem CBERS-4/ PAN-5M; b) Escala 1:30.000, imagem Alos Palsar, com iluminação deN45W; e c) Escala 1:50.000, MDT do mapa topográfico, com iluminação de N45E

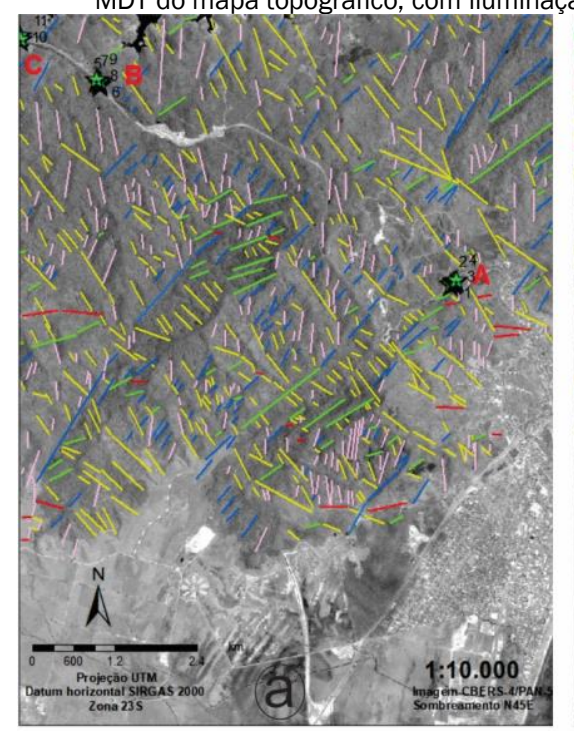

Trends dos lineamentos

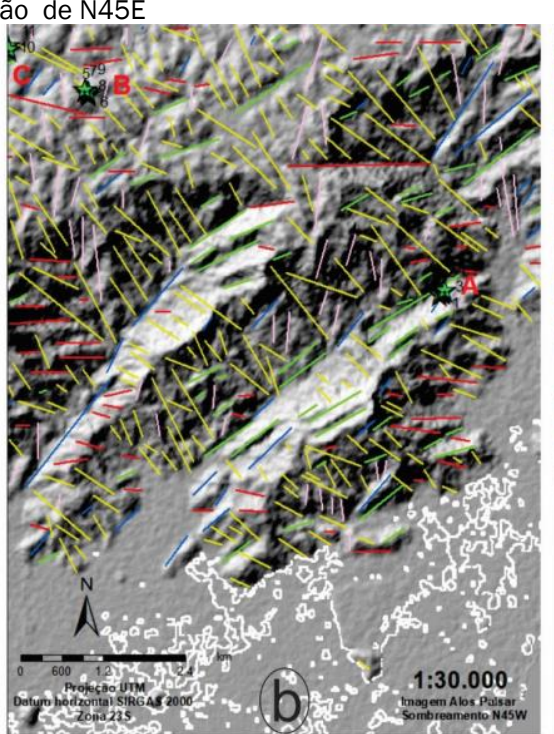

N25E - N50E

N50E - N75E

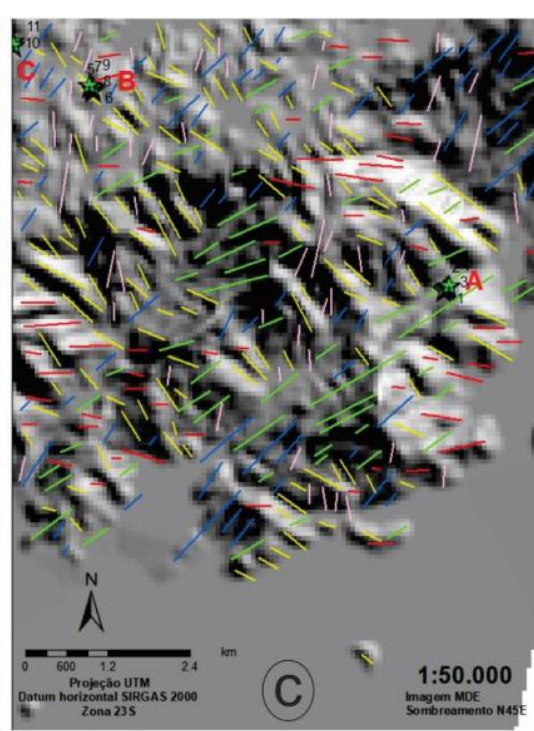

N75E - N90E - N75W

N75W - N15W

Fonte: A) Imagem CBERS-4/ PAN-5M; B) imagem Alos Palsar e C) imagem produzida pelos autores

A escala 1:10.000, principalmente na roseta de frequência, não é representativa para o G1, de direção média em torno de N65E; por outro lado, existe um trend N30-50E (Figura 6) que não corresponde a nenhum dos grupos de fraturas identificados nas scanlines (Figura 3). Tanto a frequência como o comprimento têm um bom ajuste com o grupo G2, no entanto os trends de lineamentos estão deslocados com relação à média do G3 para as fraturas. Ao contrário do que ocorre nas scanlines do local A, é notável que os lineamentos de mesma direção que o G2 (NNW-NNE) são muito menos frequentes que os de direção NW. O G4 não está presente nessa escala.

A escala 1:30.000 é a mais representativa para o G1, apesar do trend com máximo em N50-60E (Figura 6) também estar levemente deslocado com relação à média do G1 (N65E) (Figura 3). O Grupo G2 é pouco expressivo, mas ajusta-se bem à média das fraturas desse grupo. Essa escala apresenta maior espalhamento no quadrante NW, no entanto, a média ( N50W) é praticamente coincidente a de G3; destaca-se que os valores entre N50-70W são mais abundantes. 0 trend EW tem bom ajuste com G4.

Na escala 1:50.000, a dispersão da direção NE é menor na roseta de comprimentos e apresenta um trend com um máximo em N50E (Figura 6) que também está deslocado com relação à média do G1 (N65E) (Figura 3). No entanto, esta escala é a mais representativa desse grupo de fraturas, pois o trend N60-70E é relativamente frequente; por outro lado, é a menos representativa para o grupo G2. Os lineamentos NW são frequentes e a sua média é quase coincidente com a do G3. O G4 é pouco expressivo, mas aparece, de forma semeIhante ao que ocorre nas scanlines.

A escala 1:10.000 é a que mais apresenta diferenças com relação aos grupos de fraturas e as escalas 1:30.000 e 1:50.000 representam melhor todos os grupos. É provável que as scanlines, que somam um total de $224 \mathrm{~m}$ de trechos não contínuos, não tenham proporcionado um levantamento representativo dos grupos de fraturas, principalmente quanto às frequências das fraturas. As maiores diferenças aparecem na escala 1:10.000, cujo traçado foi realizado diretamente na imagem de satélite, ao passo que os mapas das escalas 1:30.000 e 1:50.000, com trends de lineamentos mais semeIhantes entre si, foram elaborados sobre MDE e MDT, respectivamente. Possíveis explicações para as diferenças observadas no quadrante NE são:

- As direções em torno de N30-50E podem ser condicionadas pelos gradientes topográficos acentuados das encostas de direção NW, mais expressivas no relevo de escarpas. Nestas, a estruturação do relevo é em grande parte associada ao G3. Assim, parte dos lineamentos NE não refletiriam estruturas, mas representariam drenagens curtas nas encostas de direção NW.

- Nas scanlines, as fraturas do G1 são em grande parte resultado da reativação da foliação ( N60E). No entanto, 
nas rochas em que a foliação não é expressiva, é possí

- $\quad$ vel que as direções N30-50E representem a atitude ideal com relação aos esforços que geraram G1. Como se verá mais adiante, nos granitos não foliados aparecem lineamentos com direção média N45E, estando ausente a direção N60E, favorecendo esta hipótese.
Levando em conta que os mapas de diferentes escalas provavelmente se complementam, e que ainda inexistem dados suficientes de campo para eleger um deles como o mais representativo dos grupos de fraturas na região, serão usadas as rosetas de soma de todas as escalas e de comprimentos, para as análises a seguir.

Figura 6 - À esquerda, diagramas de rosetas das direções das fraturas com mergulhos superiores a $60^{\circ}$. À direita, rosetas de comprimento dos lineamentos. As direções médias dos grupos de fraturas G1 a G4 são mostrados como traços nas rosetas de lineamentos

\section{Fraturas}

Local A

(sl 01 a 04)

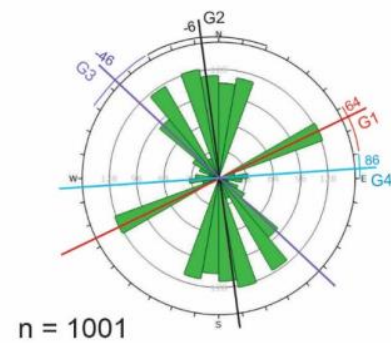

Local B e C (sl 05 a 11)

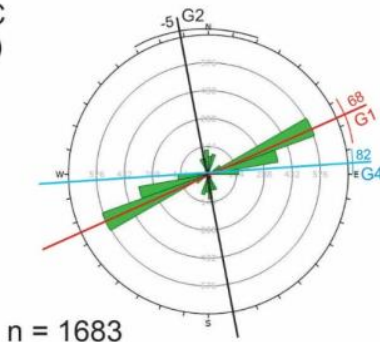

Escala

$1: 10.000$

$1: 30.000$

Lineamentos - Área total Comprimento

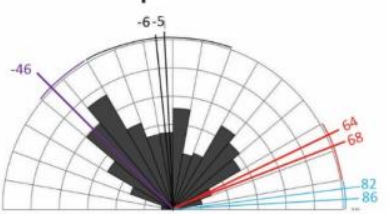

Soma do comprimento $=213.490 \mathrm{~m}$

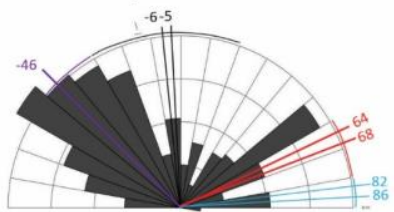

Soma do comprimento $=198.819 \mathrm{~m}$

$1: 50.000$

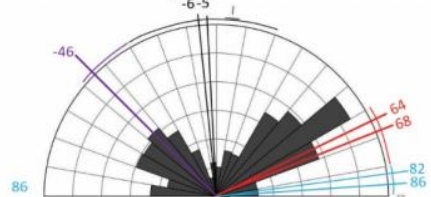

Soma do comprimento $=149.553 \mathrm{~m}$

Soma

Escalas

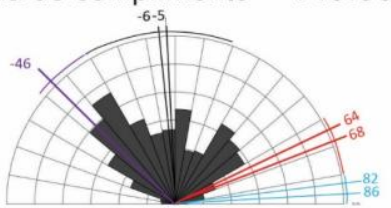

Soma do comprimento $=561.862 \mathrm{~m}$

Fonte: elaborada pelos autores.

\subsection{Trends de lineamentos em relação a unidades litológicas e fatores geomorfológicos}

De um modo geral, a maioria dos trends relacionados aos grupos de fraturas e ao trend N30-50E aparecem na maioria das

unidades dos fatores analisados, no entanto, essas unidades contrastam com relação à intensidade dos trends; essa intensidade foi classificada em Forte, Média, Fraca e Ausente (Tabela 3).

Na Tabela 3 e na Figura 7, o trend de lineamentos relacionado ao G3 ocorre em todas as unidades, principalmente com intensidade Forte e secundariamente Média. Foram medidas poucas fraturas de direção WNW (N60-70W), sendo necessário mais levantamentos de campo para confirmar se essas fraturas são tão abundantes como parecem nos mapas de lineamentos. Em seguida ao G3, destacam-se os trends NE ( N30$50 E)$ e o G1, com predomínio das classes Média e Forte. Para G2, predominam as classes Média e Fraca e o G4 está predominantemente na classe Fraca.

Nota-se que o trend NE sobressai onde G1 é da classe Fraca ou Ausente, fortalecendo a hipótese de que o trend NE aparece mais em algumas unidades litológicas ( $m X, G n$, Ogn e $Y$ ) em que a foliação não controla, de forma significativa, fraturas do quadrante NE. 
Tabela 2 - Intensidade dos trends de comprimento de lineamentos nas unidades de cada fator analisado. Tons de cinza foram utilizados para facilitar a comparação

\begin{tabular}{|c|c|c|c|c|c|}
\hline \multicolumn{6}{|c|}{ Intensidade dos trends de lineamentos relacionáveis aos Grupos de Fraturas } \\
\hline & G1 & G2 & G3 & G4 & N30-50E \\
\hline \multicolumn{6}{|c|}{ Unidades litológicas } \\
\hline $\mathrm{Mx}$ & Fraca & $\begin{array}{c}\text { Fraca } \\
\text { (N10-20E) }\end{array}$ & $\begin{array}{c}\text { Forte } \\
\text { (N20-40W e N50-60W) }\end{array}$ & Fraca & Ausente \\
\hline Gn & Ausente & Fraca & Forte (N20-60W) & Fraca & N30-40E \\
\hline Q & Forte- deslocado (N40-70E) & Ausente & Média (N40-70W) & Ausente & Ausente \\
\hline Agn1 & Média & Forte & Forte (N20-60W) & Fraca & N30-50E \\
\hline Agn2 & Forte/Médio (N50-70E) & Fraca & Forte (N20-60W) & Fraca & N20-30E \\
\hline Ogn & Ausente & Fraca & Média (N40-70W) & Fraca & N30-40E \\
\hline$\square$-gn & Média & Média & Forte (N30-70W) & Ausente & N30-40E \\
\hline$\square$ & Fraca & Fraca & Fraca & Fraca & N30-60E \\
\hline \multicolumn{6}{|c|}{ Unidade geomorfológicas } \\
\hline \multirow{2}{*}{$\begin{array}{l}\text { Planalto } \\
\text { Escarpas }\end{array}$} & Fraca & \multirow{2}{*}{$\begin{array}{l}\text { Média } \\
\text { Média }\end{array}$} & \multirow{2}{*}{$\begin{array}{l}\text { Forte (N20-50E) } \\
\text { Forte (N20-70E) }\end{array}$} & \multirow{2}{*}{\multicolumn{2}{|c|}{$\begin{array}{l}\text { N20-50E } \\
\text { N30-60E }\end{array}$}} \\
\hline & Média & & & & \\
\hline \multicolumn{6}{|c|}{ Índice de Concentração de Rugosidade (ICR) } \\
\hline Baixo & Média & Média & $\begin{array}{c}\text { Média } \\
\text { (N20-60E) }\end{array}$ & Fraca & N30-60E \\
\hline Médio & Média & Média & Média (N20-60W) & Ausente & N30-60E \\
\hline Alto & Média & Fraca & Média (N30-60W) & Ausente & Fraca \\
\hline M. Alto & Forte & Média & Forte (N20-70W) & Fraca-médio & Fraca \\
\hline \multicolumn{6}{|c|}{ Padrão de drenagens } \\
\hline P2 & Média & Fraca & $\begin{array}{l}\text { Média-Forte } \\
\text { (N30-60W) }\end{array}$ & Fraca & Ausente \\
\hline P3 & Média & Fraca & Forte (N20-50W) & Fraca & Ausente \\
\hline P4 & Ausente & Média & Média (N40-50W) & Ausente & N30-50W \\
\hline P5 & Fraca & Fraca & Forte (N20-40W) & Ausente & Ausente \\
\hline P6 & Ausente & Forte & Forte (N20-50W) & Média & N20-50E \\
\hline
\end{tabular}

Fonte: elaborada pelos autores.

Figura 7 - Unidades litológicas na área de estudo (esquerda) e suas rosetas de comprimento de lineamentos (direita), considerando a soma das escalas das imagens analisadas

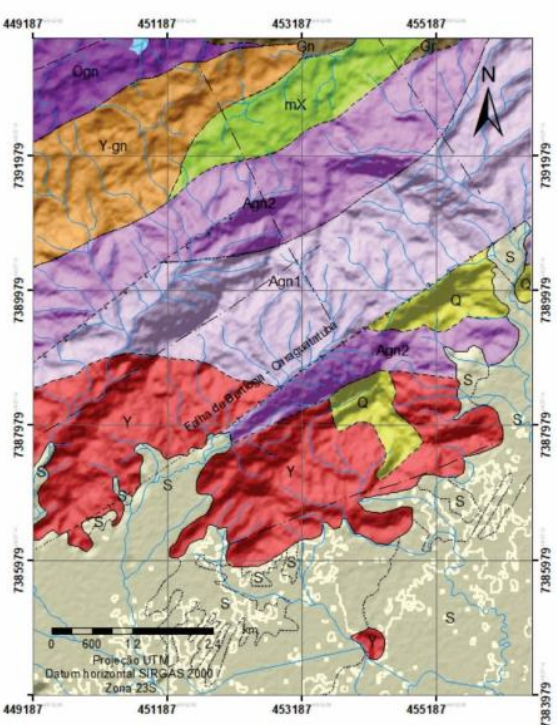

Fonte: modificado de Chiodi Filho et al. (1983). Imagem Alos Palsar

A Tabela 3 e a Figura 8 mostram que as unidades geomorfológicas, planalto e escarpa, são similares entre si com relação à intensidade dos trends de lineamentos, indicando também grande dispersão de direções. É provável que isso aconteça devido à escala de pouco detalhe do mapa, não compatível com a análise.
Granitos

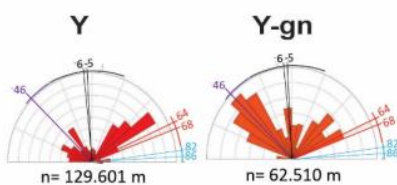

Litologia

CENOZOICO
Quaternário

S. Sedimentos aluviais

Pré-cambriano

Granitos

Y.

Agn1: Augen gnaisse com biotira granito

Agn2: Augen gnaisse

Ogn: migmatito com estruturas difusas

Rochas paraderivadas

$m X:$ Micaxistos com magnetita e quartzitos

Gnaisse com quartzitio e calcossilicato

Q. Silimanita quarzitos

\section{Ortognaisses}

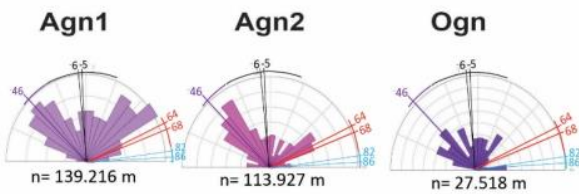

Rochas paraderivadas

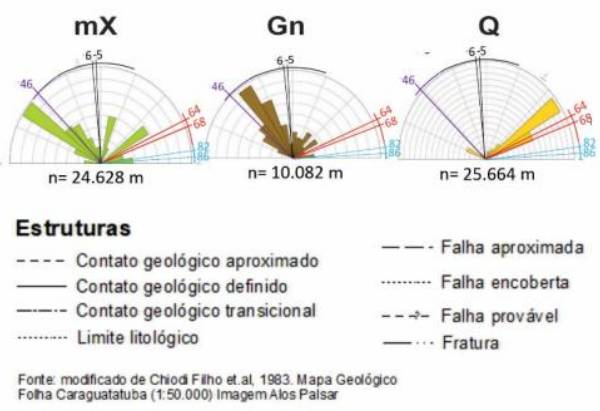

Como esperado, o mapa de ICR mostra que as áreas de maior rugosidade (Muito Alta e Alta) predominam nas áreas de escarpas, enquanto os índices médio e baixo ocorrem nas áreas de planalto e nas planícies costeiras (Figura 9). 
Figura 8 - Rosetas de comprimento para as unidades de relevo, considerando a soma das escalas

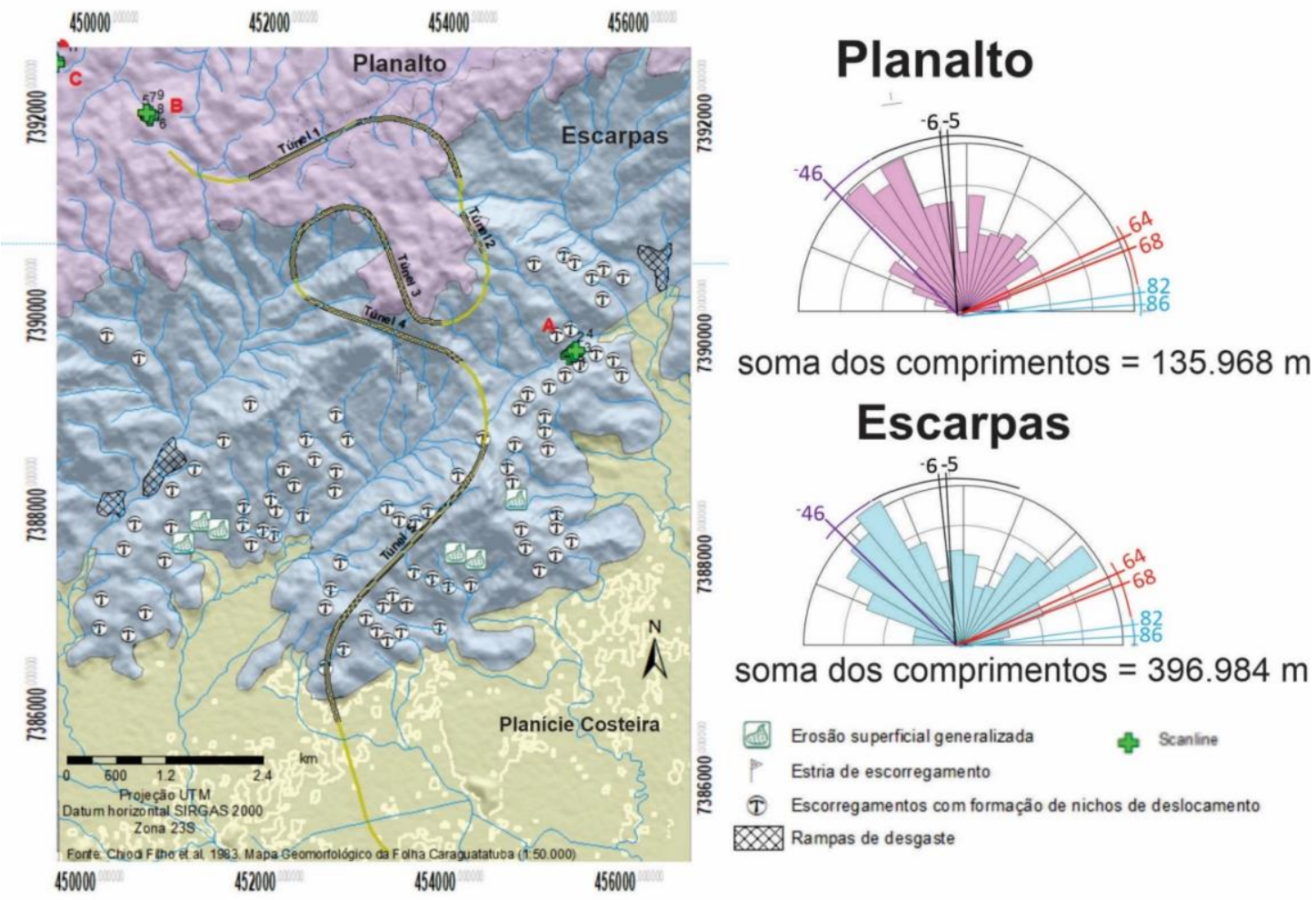

Fonte: modificado de Chiodi Filho et al. (1983). Imagem Alos Palsar

Nas rosetas de comprimento, as classes de ICR muito alto e alto melhor destacam os trends G1 e G3, na classe de intensidade Forte. Isto provavelmente decorre da erosão mais intensa em relevos mais acidentados, favorecendo a manifestação das estruturas geológicas sob a forma de lineamentos, como concluído por Fernandes e Rudolph (2001). Assim, é provável que as unidades ICR não revelem a existência de configurações distintas de sistemas de fraturas, mas apenas graus de rugosidade que levam a graus distintos de manifestação das fraturas como lineamentos.

Foram identificadas seis unidades de padrões de drenagem (P1 a P6). A unidade P1 corresponde à planície litorânea, onde os lineamentos são praticamente ausentes (Tabela 4 e Figura 10).

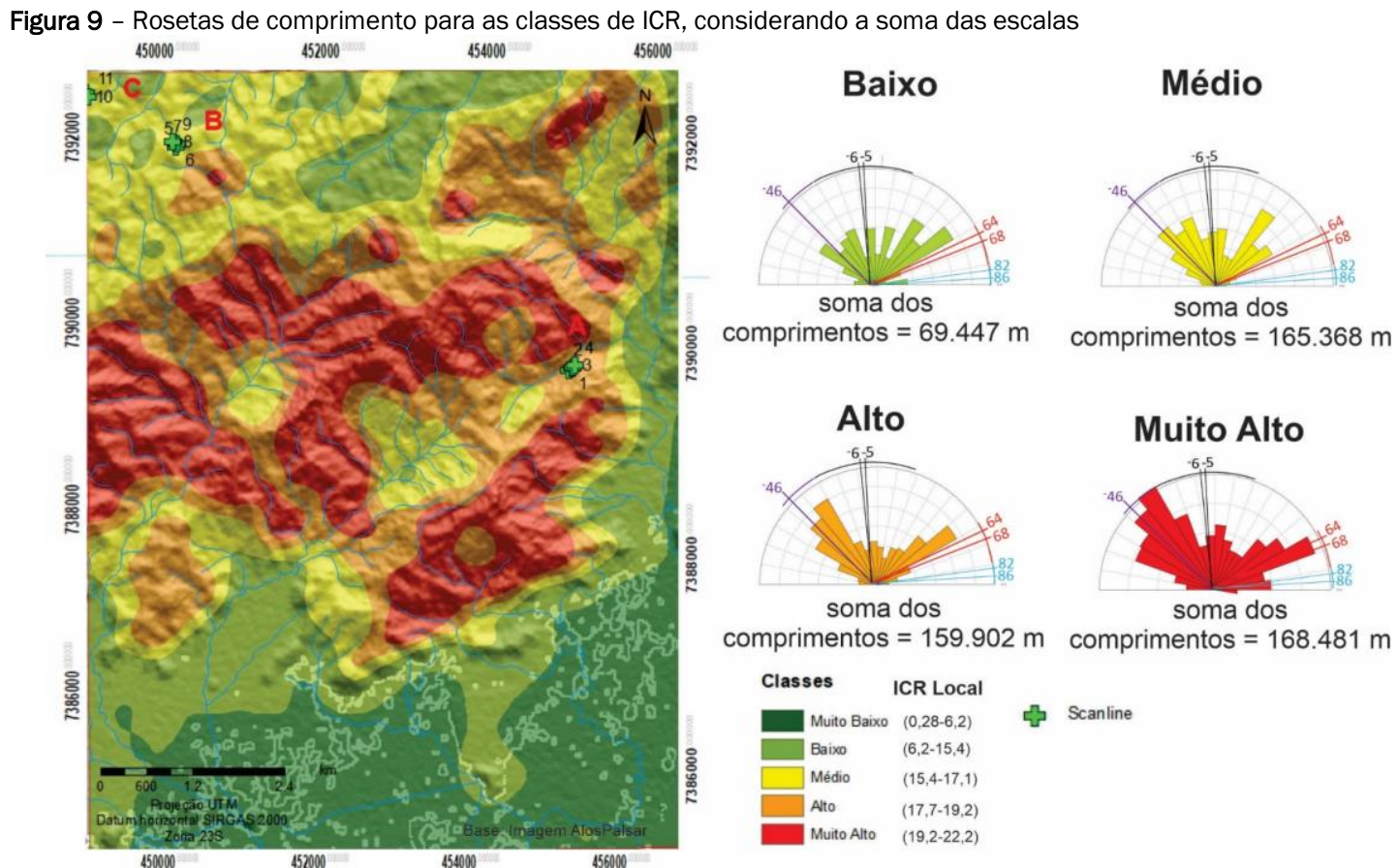


Fonte: elaborada pelos autores

Tabela 3 - Características dos diferentes padrões de drenagem definidos

\begin{tabular}{|c|c|c|c|c|}
\hline Padrão de Drenagem (P) & Densidade & Grau de estruturação & Assimetria & Estrutura \\
\hline P1 & Baixa & Fraco & Fraca & Paralela \\
\hline P2 & Média & Fraco & Forte & Paralela \\
\hline P3 & Alta & Forte & Forte & Retangular \\
\hline P4 & Média & Moderado & Forte & Retangular \\
\hline P5 & Média & Fraco & Fraca & Retangular \\
\hline P6 & Média & Moderado & Fraca & Retangular \\
\hline
\end{tabular}

Fonte: elaborada pelos autores

As rosetas de comprimento de lineamentos mostram que tais unidades são semelhantes com relação ao trend G3. Os outros trends mostram contrastes variáveis. 0 maior contraste diz respeito ao trend N30-50E, Forte nas unidades P4 e P6, mas ausente nas demais. Esses contrastes sugerem que os padrões de drenagens têm bom potencial para diferenciar unidades com configurações de fraturas distintas. Como nas unidades litológicas, o trend N30-50E tende a ser mais frequente onde G1 é menos intenso.
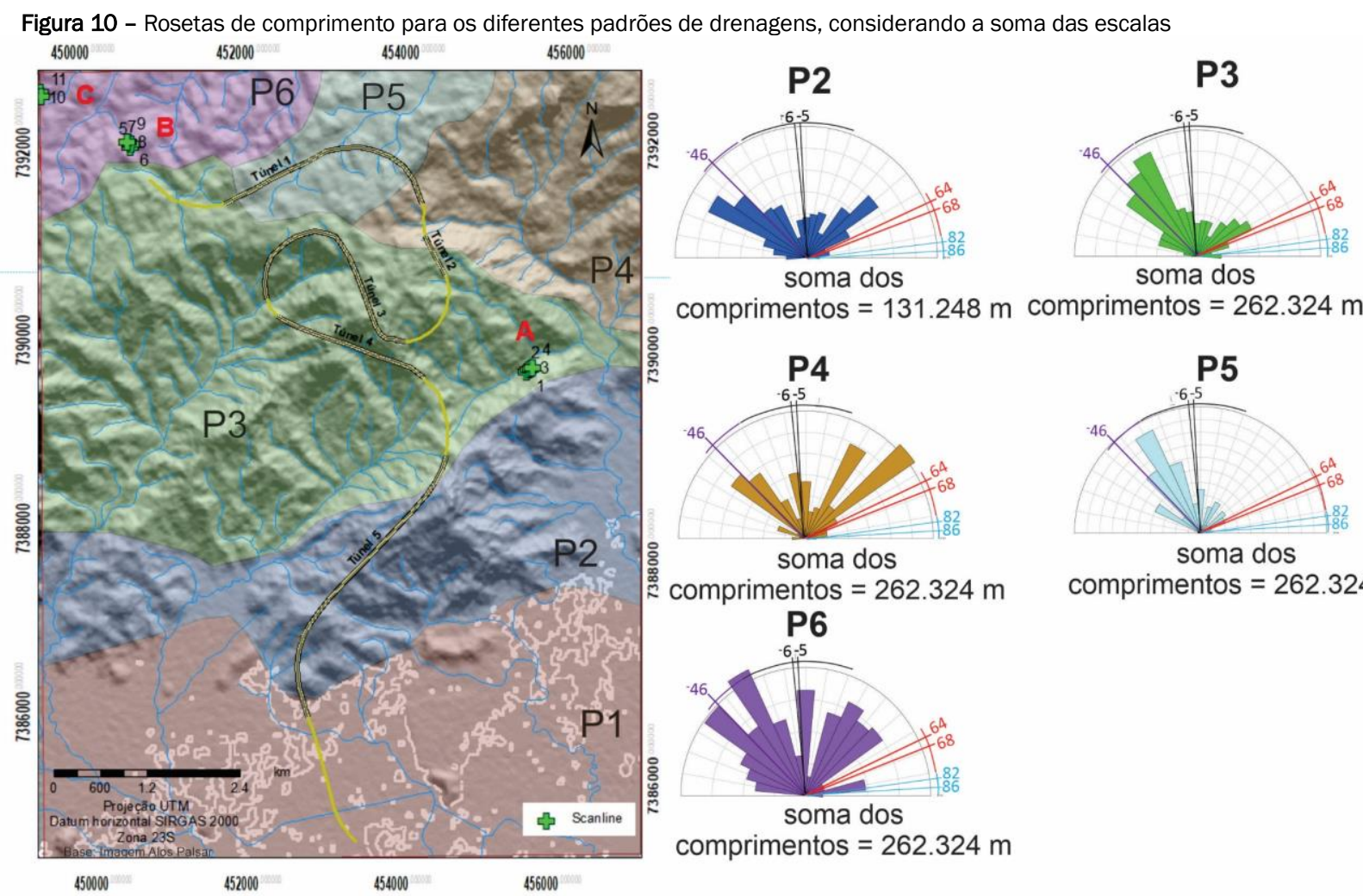

Fonte: elaborada pelos autores

\section{CONSIDERAÇÕES FINAIS E CONCLUSÕES}

A utilização conjunta de levantamentos sistemáticos de fraturas e de traçado de lineamentos é útil em análises preliminares dos trends estruturais em aquíferos fraturados. Na área de estudo, esta análise indicou a necessidade de mais levantamentos de campo para aquisição de dados representativos dos vários grupos de fraturas. Verificou-se que o trend N30$50 E$ de lineamentos não ocorre onde foram levantadas as scanlines. Esse trend de lineamentos pode estar relacionado ao controle topográfico, em vez de estrutural, ou à variação na atitude da foliação, ou ainda a ausência desta. O trend NW (G3) se manifesta com maior intensidade nos lineamentos e o NS (G2) nos afloramentos. Cabe ressaltar que os lineamentos podem ser representativos apenas para fraturas de mergulhos elevados. Assim, os levantamentos de campo são fundamentais tanto para identificar fraturas de mergulhos baixos como para caracterizar o potencial fluxo de água em cada grupo de fraturas.

Coletar dados de fraturas em todos os tipos litológicos é relevante, pois pode haver grupos de fraturas exclusivos de algumas unidades. $\mathrm{Na}$ área de estudo, os granitos maciços apresentam intensidades de trends muito contrastantes com relação às demais litologias.

Interpretar lineamentos em várias escalas, incluindo as de detalhe, deve proporcionar uma maior representatividade dos vários trends de fraturas; considera-se que as rosetas de soma de comprimentos são mais adequadas para verificar o grau de intensidade de ocorrência dos trends. Quanto aos ma- 
teriais a utilizar na interpretação de lineamentos, concluiu-se que os mapas de lineamentos traçados sobre MDE e MDT (1:30.000, 1:50.000) são semelhantes entre si, mas contrastam com o mapa de lineamentos traçado em imagem de satélite (1:10.000). Ainda não se dispõe de dados de campo suficientes para indicar qual material proporciona traçados mais representativos dos grupos de fraturas, mas é provável que os modelos digitais, por permitirem iluminações variadas, produzam resultados mais completos.

Mapas litológicos e geomorfológicos devem ter detalhe compatível com a escala de análise. Na área de estudo, as unidades litológicas e de padrões de drenagens mostraram o meIhor potencial para delimitar domínios estruturais distintos, pois as suas unidades apresentam trends melhor definidos e mais contrastantes com relação aos grupos de fraturas.

Considerando as evidências de fluxo por fraturas em campo e a direção do SHmax atual, é possível que os quartzitos e augen-gnaisses 1 e 2 (Q, Agn1 e Agn2) sejam mas favoráveis ao fluxo devido à maior intensidade do trend N30-50E e G1. No granito maciço $(\mathrm{Y})$, apesar da intensidade forte do trend $\mathrm{N} 30$ $50 E$, os outros trends são de intensidade fraca, o que potencialmente pode prejudicar a conexão entre fraturas.

As unidades P4, P5, P2 e P3 dos padrões de drenagem podem ser mais propícias ao fluxo de água subterrânea, devido à maior ocorrência de fraturas de direção NE e ENE. É importante lembrar que esta hipótese deve ser validada em futuros trabalhos de campo.

Considera-se que a identificação de trends de fraturas e de lineamentos e dos fatores com potencial de delimitar domínios estruturais é um passo importante para a caracterização de em aquíferos fraturados. Essa etapa é fundamental para várias aplicações, como na elaboração de modelos conceituais hidrogeológicos e na minimização de riscos em obras de engenharia.

\section{AGRADECIMENTOS}

Os autores agradecem à CAPES pelo apoio financeiro, ao Centro de Pesquisas em Águas Subterrâneas (CEPAS/USP) pelo apoio de campo, à Universidade Federal de Ouro Preto, pelo apoio institucional, e à Concessionária Rodovia dos Tamoios S/A, pela disponibilização de dados e apoio na pesquisa.

\section{REFERÊNCIAS}

ALMEIDA F.F.M., HASUI Y., BRITO NEVES B.B., FUCK R.A. As províncias estruturais brasileiras. In: VIII Simpósio de Geologia do Nordeste, Atas, p.363-391. Campina Grande, PB, 1977.

ASSUMPÇÃO, M.; DIAS, F.L; ZEVALLOS, I.; NAIBOFF, J. 2016. Intraplate stress field in south america from earthquake focal mechanisms. Journal of south american earth sciences. $19 \mathrm{p}$. https://doi.org/10.1016/i.jsames.2016.07.005

ARGYRIUS, A.V; TEEUW, R.M.; SOUPIOUS, P.; SARRIS, A. Neotectonic control on drainage systems: GIS-based geomorphometric and morphotectonic assessment for Crete, Greece. Journal of Structural Geology, v. 104, p. 93-111, nov. 2017. https://doi.org/10.1016/j.jsg.2017.10.002
CAINE, J.S., AND TOMUSIAK, S.R.A. Brittle structures and their role in controlling porosity and permeability in a complex Precambrian crystalline-rock aquifer system in the Colorado Rocky Mountain Front Range. Geological Society of America Bulletin, v. 115, p. 1410-1424, 2003. https://doi.org/10.1130/B25088.1

CHIODI FILHO, C.; CHIEREGATI, L. A.; THEODOROVICZ, A. M. G.; THEODOROVICZ, A.; MENEZES, R. G.; RAMALHO, R.; BATOLLA JR., F. Geologia e recursos minerais das folhas de Natividade da Serra e Caraguatatuba. In: JORNADA SOBRE A CARTA GEOLÓGICA DO ESTADO DE SÃO PAULO EM 1:50.000. 1., 1983. Pró-Minério, IPT. p. 8-29. São Paulo, 1983

CHRISTOFOLETTI, A. Geomorfologia: análise de bacias hidrográficas. Editora Edgard Blucher. São Paulo, 1980.

COOK P.G. A guide to regional groundwater flow in fractured rock aquifers. CSIRO Land and water, Glen Osmond, SA, 115 p. Austrália, 2003.

DEPARTAMENTO DE ÁGUAS E ENERGIA ELÉtRICA - DAEE. Mapa de águas subterrâneas do Estado de São Paulo: escala 1:1.000.000. Nota explicativa: DAEE, IG (Instituto Geológico), IPT (Instituto de Pesquisas Tecnológicas do Estado de São Paulo), CPRM (Serviço Geológico do Brasil), 119p. São Paulo, 2005.

DUARTE COSTA, W. Hidrogeologia dos meios fissurados. In: FEITOSA, F. A. C.; MANOEL FILHO, J.; FEITOSA, E. C.; DEMETRIO, J. G. A. (orgs) Hidrogeologia: conceitos e aplicações. 3. ed, Rio de Janeiro, CPRM (Serviço Geológico do Brasil), LABHID, p. 121-151. 2008.

FERNANDES, A.J., RUDOLPH, D. The influence of Cenozoic tectonics on the groundwater-production capacity of fractured zones: a case study in São Paulo, Brazil. Hydrogeology Journal, $\begin{array}{llll}\text { v. } 9, & \text { p. } & 151-167 .\end{array}$ https://doi.org/10.1007/s100400000103

FERNANDES, A.J.; PERROTA, M.M.; SALVADOR, E.D.; AZEVEDO, S.G.; GIMENEZ FILHO, A.; STEFANI, F.L.; PAULON, N. Aquíferos fraturados. In: GOVERNO DO ESTADO DE SÃO PAULO (ed.) Mapa de águas subterrâneas do Estado de São Paulo (escala 1:1.000.000). DAEE/IG/IPT/CPRM, p. 66-84. São Paulo, 2005.

FERNANDES, A.J.; PERROTA, M.M.; SALVADOR, E.D.; AZEVEDO, S.G.; GIMENEZ FILHO, A.; STEFANI, F.L.; PAULON, N. Potencial dos aquíferos fraturados do Estado de São Paulo: condicionantes geológicos. Águas Subterrâneas, v. 21, p. 63-84. São Paulo, 2007. https://doi.org/10.14295/ras.v21i1.16168

FERNANDES, A.J.; FIUME, B., BERTOLO, R.; HIRATA, R. Modelo geométrico de fraturas e análise de tectônica rúptil aplicados ao estudo do fluxo do aquífero cristalino, São Paulo (SP). Geologia USP, Série Científica, v.16, p.71-88. São Paulo, 2016. https://doi.org/10.11606/issn.2316-9095.v16i3p71-88 
FERNANDES, A.J., ROULEAU, A., VARGAS, E. Structural geology applied to fractured aquifer characterization. eBook Ground water Project, Online Plataform for Groundwater Knowledge. 2021.

GROHMANN, C.H. AND CAMPANHA, G.A.C. OpenStereo: open source, cross-platform software for structural geology analysis. Presented at the AGU 2010 Fall Meeting, San Francisco, CA, 2010.

HASUI, Y.; DANTAS, A.S.; CARNEIRO, C.D.R.; BISTRICHI, C.A. O Embasamento Pré-Cambriano e Eopaleozóico em São Paulo. In: INSTITUTO DE PESQUISAS TECNOLÓGICAS-IPT. Mapa geológico, escala 1:500.000, p.12-45 (nota explicativa). São Paulo, 1981.

HIRUMA, S. T.; RICCOMINI, C. Análise Morfométrica em Neotectônica: o exemplo do Planalto de Campos do Jordão, SP. Revista do Instituto Geológico, São Paulo, v. 20, n. 1/2, p. 519, 1999. https://doi.org/10.5935/0100-929X.19990001

HOBBS, W. Lineaments of the Atlantic Border Region. Geological Society. American Bulletin, 15, p. 483-506, 1904. https://doi.org/10.1130/GSAB-15-483

HORTON, R.E. Erosional development of streams and their drainage basins: hyfrophysical approach to quantitative morphology. Bulletin of the Geological Society of America 56, v. 2 p. 75-370, 1945. https://doi.org/10.1130/00167606(1945)56[275:EDOSAT]2.0.CO;2

HOWARD, A.D. Drainage Analysis in Geologic Interpretation: A Summation. American Association of Petroleum. Geologist Bulletin, v. 51, p. 2246-2259, 1967. https://doi.org/10.1306/5D25C26D-16C1-11D7$\underline{8645000102 C 1865 \mathrm{D}}$

INSTITUTO NACIONAL DE PESQUISAS ESPACIAIS - INPE. Câmeras Imageadoras CBERS-3 e 4. Dispon "ivel em: http://www.dgi.inpe.br/CDSR/index.php. Acesso em 15 jun. 2019.

MABEE, S. E HARDCASTLE, K. Analyzing outcrop-scale fracture features to supplement investigations of bedrock aquifers. Hydrogeology Journal, v. 5, p. 21 - 36. 1997. https://doi.org/10.1007/s100400050106

MABEE, S., CURRY, P., HARDCASTLE, K. C. Correlation of lineaments to ground water inflows in a bedrock tunnel. Ground water, $\quad$ v. 40, p. 37-43, 2002. https://doi.org/10.1111/j.1745-6584.2002.tb02489.x

O'LEARY D., FRIEDMAN J., POHN H. Lineaments, linear, lineation - some proposed new standards for old terms. Geol Soc Am Bull, v. 87, p. 1463-1469, 1976.

https://doi.org/10.1130/00167606(1976)87<1463:LLLSP $\mathrm{N}>2.0 . \mathrm{CO} ; 2$
PINO, D.S., ROY, D.W, ROULEAU, A., FERNANDES, A.J., BERTOLO, R.A. Linhas de levantamento estrutural: correlação do viés de orientação a partir de planilahs eletrônicas. Revista do Instituto Geológico, v. 40, n. 3, p. 49-74. São Paulo, 2019. https://doi.org/10.33958/revig.v40i3.675

QUEIROZ, G.L., SALAMUNI, E., NASCIMENTO, E.R. AzimuthFinder: ferramenta para a extração de dados e apoio na análise estrutural. Revista do Instituto de Geociências USP, Série Científica, v. 14, n.1, p. 69-80. São Paulo, 2014. https://doi.org/10.5327/Z1519-874X201400010005

ROCKSCIENCE. Dips: software user's guide. v. 6.0. Rocscience Inc. Toronto, Ontário, Canada, 2013.

SADOWSKI BR. A megafalha de cubatão. Bol ig-usp, séria científica, v. 22, p. 15-28, 1991.

https://doi.org/10.11606/issn.2316-8986.v22i0p15-28

SAMPAIO, T.V.M, AUGUSTIM, R. Índice de Concentração da Rugosidade: uma nova proposta metodológica para o mapeamento e quantificação da dissecação do relevo como subsídio a cartografia geomorfológica. Revista Brasileira de Geomorfologia, v. 15, n. 1, p. 47-60, 2014. https://doi.org/10.20502/rbg.v15i1.376

SIQUEIRA E HACKSPACHER. Evolução tectônica e denudacional da serra do mar (se/brasil) no limite entre o cretáceo superior e paleoceno, utilizando análises de traços de fissão e uth/he em apatitas. Revista Brasileira de Geomorfologia, v. 12, n. 3, p. 3-14, 2011. https://doi.org/10.20502/rbg.v12i0.254

SOARES, P.C. E FIORIA. Lógica e sistemáticana análisee interpretação de fotografias aéreasem geologia. Notícias Geomorfológicas, v. 16, n. 32, p. 71-104, 1976.

SURRETTE, M., ALLEN, D.M. Quantifying heterogeneity in variably fractured sedimentary rock using a hydrostructural domain. Geological Society of America Bulletin, v. 120, n. 1-2, p. 225-237, 2008. https://doi.org/10.1130/B26078.1

UMILI, G., BONETTO, S., FERRERO, A. M., AND M. R. MIGLIAZZA. An innovative multiscale approach for the characterization of rock masses subject to tunnel excavation. Isrm 1st international conference on advances in rock mechanics Hammamet, Tunisia, 2018. 